http://dx.doi.org/10.5007/1980-3532.2012n8p38

\title{
Lumpemproletarização Juvenil e Contestação Social na Grande Buenos Aires
}

\section{Youth Lumpemproletarization and Social Challenge Greater Buenos Aires}

\author{
Lisandro Rodrigues Braga \\ Doutorando em Sociologia pela Universidade Federal de Goiás (UFG) \\ Professor da Universidade Federal de Mato Grosso do Sul (UFMS) \\ lisandrobraga@gmail.com
}

\begin{abstract}
Resumo: O presente artigo pretende abordar a dinâmica da lumpemproletarização na Argentina, sua relação com o desencadeamento de diversas lutas, o surgimento de vários movimentos e práticas de resistências sociais (movimentos de trabalhadores desempregados, assembleias populares, autogestão nos bairros, realização de bloqueios de ruas, estradas e pontes etc.) e a ampla participação da juventude nessas ações. Para isso, analisaremos o engendramento de um novo padrão de acumulação, expresso em um novo regime de acumulação (acumulação flexível para Harvey, 2008 e acumulação integral para Viana, 2009), algumas de suas principais formas e determinações, assim como, a intensa lumpemproletarização da juventude e o caráter contestador de suas lutas sociais na Grande Buenos Aires (GBA), entre os anos de 1995-2002.
\end{abstract}

Palavras-chave: Acumulação integral. Lumpemproletarização. Movimento Piqueteiro. Contestação social. Juventude .

\begin{abstract}
This article seeks to address the dynamics of lumpemproletarization in Argentina, its relationship with the onset of various struggles, the emergence of various movements and practices of social resistance (movements of unemployed workers, popular assemblies, self-management in the neighborhoods, blockade of streets, roads and bridges etc..) and broad participation of youth in these actions. For this, we analyze the engendering of a new pattern of accumulation, expressed in a new regime of accumulation (flexible accumulation for Harvey, 2008, and full cumulation to Viana, 2009), some of their main forms and determinations, as well as the intense lumpemproletarization youth and oppositional character of their social struggles in Greater Buenos Aires (GBA), between the years 19952002.
\end{abstract}

Keywords: Full cumulation. Lumpemproletarization. Piquetero movement. Social protest. Youth.

Originais recebidos em: 22/08/2013

Aceito para publicação em: 05/09/2013

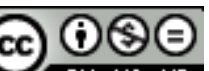

Comercial-Vedada a criação de obras derivadas 3.0 Unported License. 


\title{
Acumulação de capital e classe marginal na Argentina
}

\author{
A realidade concreta do capitalismo em fase de acumulação integral,
} expressada por alguns teóricos marxistas, aponta o processo de lumpemproletarização como uma de suas principais consequências sociais (VIANA, 2009; BRAGA, 2013a). Em fases como essa, tal processo é singular, pois seu caráter expansivo mantém por um tempo cada vez maior uma quantidade enorme de indivíduos oriundos de outras classes sociais em uma mesma classe social marginalizada na divisão social do trabalho. Tratase do lumpeproletariado. ${ }^{2}$ Em países de capitalismo subordinado, como é o caso argentino, esse processo tem ocorrido de forma intensificada, contribuindo para uma acelerada expansão da miséria e de tudo que se relaciona a ela (subemprego, fome,

\footnotetext{
1 Apesar da análise de Harvey (2008) coincidir em diversos pontos com a análise de Viana (2009), optamos pelo conceito cunhado pelo segundo visto que esse nos parece melhor expressar as transformações operadas no modo de produção capitalista a partir da década de 1970. Fundamentalmente, o destaque que esse autor apresenta para o papel da luta de classes nas transformações das três principais formas do regime de acumulação integral: o toyotismo e seus similares (forma organizacional das relações de trabalho), o neoliberalismo (como principal forma de regularização das relações sociais) e o neoimperialismo (relações internacionais entre capitalismos imperialistas e subordinados). De acordo com Viana, "o que se busca é concretizar uma acumulação integral, simultaneamente intensiva e extensiva através da extensão do processo de mercantilização das relações sociais e da busca de ampliação do mercado consumidor, mesmo que esta busca se caracterize, em parte, pela produção personalizada, e também pelo aumento da intensificação da exploração da força de trabalho através do aumento de extração de mais-valor relativo e absoluto. No caso da especialização ou do que alguns chamam de pluri-especialização(Coriat), trata-se de uma especialização ampliada, onde ao invés do trabalhador se dedicar a apenas uma atividade passa a se dedicar a várias, embora se mantenha afastado do controle do processo de trabalho, o que significa especialização no processo de execução, e continue não executando certas funções práticas que ficam a cargo de outros trabalhadores. No caso dos trabalhadores, o que ocorre é uma intensificação da exploração com a retirada de seus direitos já conquistados e da formação de um mercado de trabalho inflexível, onde os trabalhadores se submetem a subcontratação, ao desemprego, etc. No caso da subcontratação (bem como no caso das horas extras), o que se vê é um aumento disfarçado da jornada de trabalho, o que significa aumento de extração de maisvalor absoluto. Aliás, mais-valor relativo e mais-valor absoluto andam juntos no período de acumulação integral, embora isto seja constante no capitalismo, mas agora assume proporções intensas, tal como não ocorria há muito tempo na história do capitalismo (VIANA, 2009, p. 70-71).

2 "Em nossa análise, o lumpemproletariado é ressignificado na contemporaneidade a partir de uma teoria marxista das classes sociais. No entanto, não ficamos presos à análise que Karl Marx realiza sobre o lumpemproletariado, o que não significa que abandonamos as contribuições desse autor para pensar as classes sociais, mas tão somente que procuramos ir além dele sem necessariamente abandoná-lo. Em outras palavras, utilizamos as contribuições existentes ao longo de sua vasta obra para pensar o conceito de classes sociais. Dessa forma, afirmamos que o lumpemproletariado é composto pela totalidade do exército industrial de reserva (desempregados, subempregados, mendigos, sem-teto, prostitutas etc.) uma vez que os indivíduos que compõem essa totalidade possuem características em comum e que possibilitam sua definição como classe, da mesma forma divisões apontadas pelo conceito de frações de classe. Assim como as demais classes sociais do capitalismo, é o seu modo de vida que possibilita sua unificação como classe. No entanto, ao contrário das demais classes sociais que são unificadas a partir da sua posição na divisão social do trabalho capitalista, o lumpemproletariado se unifica pela condição de marginalidade na divisão social do trabalho e tal condição o torna uma classe social" (VIANA, 2012; BRAGA, 2013).
}

Em Debat: Rev. Dig., ISSNe 1980-3532, Florianópolis, n. 8, p. 38-53, jul-dez, 2012. 
desnutrição, altas taxas de mortalidade infantil, desesperança, frustração, criminalidade, vida precária e instável etc.), assim como das tensões e contestações sociais.

A crise capitalista da década de 1970 exigiu a construção de um novo regime de acumulação que tornasse possível os propósitos fundamentais do capitalismo internacional: a reprodução ampliada de capital. Para isso, foi necessário reestruturar a produção de capital, entenda-se de mais-valor, em escala global. Isto significa dizer que tanto o capitalismo imperialista, quanto o capitalismo subordinado necessitava passar por profundas mudanças nas suas esferas produtoras (reorganização das relações de trabalho), regularizadoras (Estado, instituições estatais e privadas, normas legais, sociabilidade, ideologias etc.) e nas suas relações internacionais (neoimperialismo). ${ }^{3}$

Sendo assim, compreender essa totalidade é pré-requisito para a compreensão das especificidades da acumulação integral argentina, no entanto, os propósitos desse texto exigem que tal discussão seja apresentada de forma sintética, valorizando genericamente os aspectos mais cruciais da realidade desse país.

Apesar do regime de acumulação integral na Argentina se consolidar na década de 1990, sua fase de transição inicia-se na década de 1970 com a instalação da ditadura militar (1976-1983). Não restam dúvidas que a ditadura, em nome da classe dominante internacional e de determinadas frações da classe dominante local e suas respectivas classes auxiliares, engendrou um novo regime de acumulação de capital no qual suas características fundamentais se apresentariam nitidamente após a década de 1990. Uma das metas centrais do regime militar era promover maior abertura econômica, combater a permanente intervenção estatal na economia e, fundamentalmente, eliminar os quadros mais combativos do proletariado e do sindicalismo argentino. É válido ressaltar, no entanto, que o combate ofertado pelo sindicalismo argentino da década de 60 e 70 é limitado por sua intransponibilidade de classe (burocracia sindical) e por isso suas ações não apontavam para além das fronteiras do capitalismo. Pelo contrário, estavam intimamente ancoradas na ideologia peronista do pacto social:

[...] o sindicalismo peronista tinha um caráter bifrontal: 1) conflitivo em relação ao patronato por sua história imediata e por suas funções corporativas, e 2) acordista e conciliador por sua inserção em um movimento político que colocava o pacto social no centro de seu projeto governamental (SIDICARO, 2010, p. 105-106).

O período no qual o golpe militar passa a ser articulado equivale, no contexto internacional, ao período de crise do regime de acumulação intensivo-extensivo (Cf.

\footnotetext{
${ }^{3}$ Cf. HARVEY (2008, 2008a, 2011); VIANA (2003, 2009).

Em Debat: Rev. Dig., ISSNe 1980-3532, Florianópolis, n. 8, p. 38-53, jul-dez, 2012.
} 
VIANA, 2009) no final da década de 60 que obrigava as nações neoimperialistas a buscarem soluções para a crise de acumulação, tanto nacionalmente, quanto internacionalmente. Na Argentina a ditadura militar apresentou-se como solução para as lutas entre frações da burguesia (nacional, internacional e agrária) contra os governos peronistas e a burocracia sindical aliada que constantemente dificultava as tentativas de ampliar ainda mais a extração de mais-valor das classes trabalhadoras, assim como dificultava sua transferência de um setor produtivo para outros (SIDICARO, 2010). Nesse sentido, a ditadura militar teve como beneficiários

\begin{abstract}
os grandes grupos econômicos ou holdings de capital nacional, cujas áreas de influência se expandiram em diferentes âmbitos, combinando as vantagens que lhes davam sua aproximação com os centros de decisões oficiais e a disposição de informação que, na desorganização reinante, era um recurso importante para obter lucros especulativos. A abertura da economia produziu a incorporação ao país dos capitais financeiros internacionais, cuja presença havia sido desestimulada nos três anos do segundo peronismo, o que, dada a situação mundial de excepcional liquidez, se mostraram dispostos não só a conceder empréstimos, senão a promover níveis desnecessários de endividamento externo [...] os grupos econômicos nacionais também conseguiram empréstimos externos, e quando entrou em crise o sistema lasso de endividamento internacional, no início da década de 80 , idealizaram junto com o Estado um mecanismo para nacionalizar suas dívidas que, em não poucos casos, eram auto empréstimos. O poder econômico dos atores socioeconômicos predominantes se incrementou durante a ditadura, ao mesmo tempo em que à crise das capacidades estatais em ordem política, burocrática e técnica se somavam as consequências da dívida externa, cujos serviços absorviam uma parte considerável dos recursos fiscais. Com a dívida, multiplicada por sete durante a ditadura, se agregaram na qualidade de interlocutores permanentes das relações políticas domésticas os organismos financeiros internacionais, principalmente o Fundo Monetário Internacional e o Banco Mundial (SIDICARO, 2010, p. 157-158).
\end{abstract}

Uma importante característica da acumulação integral, e que adquiriu um peso significativo na sociedade Argentina nas duas décadas posteriores à instalação da junta militar no poder diz respeito ao processo de concentração e centralização de capital nas mãos de grandes complexos oligopólicos. Juntamente com essa característica, outra resultou importante: o drástico processo de redução da produção industrial. Com o jogo da livre concorrência funcionando a pleno vapor e o estado neoliberal argentino agindo conforme deveria, isto é, subordinado aos interesses do grande capital nacional e internacional, empresas de grande poderio econômico passam a adquirir notáveis poderes de decisão política sobre os rumos da economia nacional. A expressiva marca desse poder é percebida na imensa transferência de empresas públicas, muitas vezes detentoras de mais de um terço das vendas que realiza a elite empresarial, para as mãos da iniciativa privada e na deflagração de associações entre diversos grupos econômicos 
locais e diversas modalidades de capitais estrangeiros que passaram a concentrar e centralizar a acumulação de capital no país. ${ }^{4}$

O novo regime de acumulação dominante na Argentina, nas primeiras décadas após o fim da ditadura militar, será notavelmente marcado por um amplo processo de privatização de empresas públicas; por uma expressiva concentração e centralização de capitais nas mãos de grandes complexos oligopólios com a predominância do capital estrangeiro; por um aumento expressivo da dívida privada externa argentina, que devido ao caráter subordinado do Estado nacional a torna dívida pública; por uma drástica redução da atividade industrial devido à falência de diversas empresas de pequeno e médio porte, devido ao deslocamento ${ }^{5}$ de parques industriais de determinadas regiões (Grande Buenos Aires, Córdoba, Rosário) para outras regiões (internas e externas); por uma violenta ofensiva do capital contra o trabalho indicada em uma crescente queda salarial, por uma precarização e intensificação das relações de trabalho e, fundamentalmente, por uma intensa lumpemproletarização de diversas classes sociais, com destaque para o proletariado e seu grupo etário juvenil (BASUALDO, 2002; CARRERA, CAVALLERI \& MURRUNI, 2010; SVAMPA, 2010; SCHORR, 2013).

Dentre as várias consequências desse novo regime de acumulação, destacaremos com maior profundidade aquela que diretamente interessa aos propósitos desse texto: a lumpemproletarização, isto é, o processo no qual a dinâmica da acumulação capitalista torna dispensável parcela excessiva da força de trabalho, que passa a constituir uma "população sobrante" para as necessidades exploratórias do capital.

Em nossa análise contaremos com o auxílio importantíssimo das informações fornecidas e sistematizadas pelo Programa de Investigação sobre o Movimento da Sociedade Argentina - PIMSA ${ }^{6}$ contidas, especificamente, no Documento de Trabalho

\footnotetext{
${ }^{4}$ Para maiores informações sobre o processo de concentração e centralização de capital na Argentina Cf. BASUALDO (2002).

5 "De fato, o argumento implícito na produção acadêmica ligada à 'nova divisão internacional do trabalho' é que a industrialização em áreas de baixos salários e a desindustrialização nas áreas de alta remuneração são dois lados da mesma moeda" (SILVER, 2005, p. 41).

6 "Este programa é levado adiante, desde 1993, por um conjunto de investigadores formados em distintas disciplinas, articulados em equipes de investigação que pretendem integrar as distintas aproximações ao conhecimento da realidade social de historiadores, sociólogos, antropólogos e economistas. Estas equipes de investigação foram se constituindo em distintos momentos ao longo dos últimos 24 anos, e com a realização desse programa tentamos dar continuidade e às vezes superar essa acumulação realizada no campo do pensamento científico, dando conta das profundas mudanças que tem produzido na Argentina atual como manifestação local do sistema capitalista mundial e atendendo as especificidades que se apresentam, como país dependente onde as relações capitalistas tem alcançado um alto grau de desenvolvimento. Para isso abarcamos o período ao redor dos 130 anos nos quais tem ocorrido a gênese, formação e desenvolvimento do capitalismo na Argentina" (PIMSA, 2013).

Em Debat: Rev. Dig., ISSNe 1980-3532, Florianópolis, n. 8, p. 38-53, jul-dez, 2012.
} 
número 77, intitulado A superpopulação relativa na Argentina atual: um exercício de medição ${ }^{7}$ (CARRERA, CAVALLERI \& MURRUNI, 2010).

A totalidade do lumpemproletariado é composta por uma diversidade de frações de sua classe social. Dentre essas frações podemos citar aquelas que se encontram no desemprego aberto, os subempregados (catadores de recicláveis, trabalhadores informais por conta própria, passeadores de cães etc., sem-teto, contraprestadores de serviços públicos por recebimento de políticas sociais etc.). Entre o final da década de 1960 até o ano de 2002, a sociedade argentina apresentou uma oscilação constante nas taxas de desemprego. Para melhor visualizar essa tendência oscilatória, a análise realizada pelo PIMSA foi dividida em dois momentos: de 1966 até 1988 e de 1988 até 2002. Vejamos.

Entre abril de 1966 e maio de 1988 a taxa de desemprego aberto oscilou entre um mínimo de 3,8\% e um máximo de 6,5\%. As únicas exceções nesse primeiro momento se deram nos anos de 1964 (ano de início da sistematização da taxa de desemprego aberto no país) onde a taxa alcançou os 7,5\% e, em abril de 1972, quando a mesma atinge os 7,4\%. Entre os anos de 1977 a 1980 a taxa se manteve abaixo dos 3\%. No geral a mesma oscilou entre $4 \%$ e 6,5 \% até 1973, mas a partir daí descende e oscila entre $4 \%$ ou $5 \%$. A taxa mais baixa foi registrada no mês de outubro de $1978(2,3 \%)$. No entanto, vale informar que

\begin{abstract}
essas baixas taxas nos quatro últimos anos da década de 1970 (nos anos que vão desde a chamada "reforma financeira" até as primeiras manifestações da chamada "crises da dívida", devem ser analisadas tendo presente a política de emprego que realizava o governo cívico militar: evitar a manifestação aberta do desemprego formava parte da "luta contra a subversão" já que "por detrás de cada desempregado havia um guerrilheiro em potencial". Essa política se manifestou no aumento dos empregados estatais. Na saída do governo cívico militar a taxa de desemprego aberta voltou a oscilar em valores similares aos da década de 60: entre 4,4\% em outubro de 1984 e 6,5\% em maio de 1988. (CARRERA, CAVALLERI \& MURRUNI, 2010, p. 111).
\end{abstract}

$\mathrm{O}$ segundo momento marca um maior grau de oscilação e aponta para o rompimento do seu teto histórico, quando em maio de 1989 a taxa de desemprego aberto atinge a marca de $8,1 \%$ em plena crise hiperinflacionária. Daí em diante a tendência dominante, porém com oscilações, tornou-se ascendente até chegar ao máximo de 21,5\% em maio de 2002, quer dizer alcançava quase uma quarta parte da população economicamente ativa da Argentina.

\footnotetext{
${ }^{7}$ Aquilo que é caracterizado nas análises do PIMSA como sendo superpopulação relativa equivale, em nossa análise, à totalidade do lumpemproletariado.

Em Debat: Rev. Dig., ISSNe 1980-3532, Florianópolis, n. 8, p. 38-53, jul-dez, 2012.
} 
É visível que após a crise generalizada de 2002 as taxas de desemprego baixaram, porém isso foi provocado muito mais por "maquiagens institucionais e estatais" do que por uma regressão concreta nas taxas de desemprego. Se levarmos em consideração que uma boa parte dessas taxas foi encobertas pela criação de diversos postos de trabalho altamente precarizados e/ou subemprego é possível afirmar que a realidade não seguiu tão distinta assim do que a existente no ano de 2002. A expansão do subemprego é nítida quando verificamos o crescimento gigantesco de pessoas que passaram a sobreviver da coleta de lixos e recicláveis:

Em 1989 um diretor de alto escalão de uma empresa dedicada aos serviços de limpeza estimava que na cidade de Buenos Aires mais de duas mil pessoas se dedicavam ao cirujeo. ${ }^{8}$ Em 1990, em Rosário se estimava que 10.000 pessoas viviam da ocupação de "buscadores de resíduos". Em 1999, a partir de um Censo de Coletores de Grãos dos municípios de José C. Paz y Malvinas Argentinas, se estimou em "mais de 1000 lares em ambos os municípios para cujos membros o cirujeo constitui a atividade laboral principal, e na maioria dos casos, a única fonte de renda" e para 2002, utilizando dados da Estatística Permanentes de Lares, se estimou em 10.800 os catadores de recicláveis e vendedores ambulantes da cidade de Buenos Aires e 62.000 os do conurbano bonaerense. Projetando a cifra da população desses municípios à cifra da população da região metropolitana se estima que 25.000 lares (100.000 pessoas) estariam vivendo do cirujeo e da venda ambulante. Em 2007, superada a crise econômica, se estimava que todos os dias transitavam pela cidade de Buenos Aires uns 12.000 catadores de recicláveis, a maioria proveniente do conurbano bonaerense (CARRERA, CAVALLERI \& MURRUNI, 2010, p. 154).

Além disso, outra "maquiagem estatal" amplamente utilizada foi a de não considerar desempregado os indivíduos que eram assistidos por alguma política social e que prestavam algum tipo de trabalho como contraprestação a tal benefício. Dessa forma, os paliativos oferecidos pelas políticas sociais contribuíam para encobrir o verdadeiro índice de desemprego no país, visto que tais desempregados, pré-condição para obtenção desses, já não mais engrossavam as estatísticas oficiais de desemprego. $\mathrm{Na}$ verdade, a própria existência de um grande contingente populacional necessitado de subsídios sociais para garantir minimamente sua sobrevivência revela a incapacidade do capitalismo em manter esse lumpemproletariado imenso em condições próprias da sociedade capitalista (trabalhando alienadamente e recebendo salário, por exemplo). Em outras palavras, essa classe social marginalizada da divisão social do trabalho vem constituindo uma população sobrante para o capital e que força o Estado, principal agente regularizador da acumulação capitalista, a buscar formas paliativas para tentar conter as tensões sociais promovidas por essa "classe em farrapos". Seria impossível

\footnotetext{
${ }^{8}$ Acreditamos que a tradução mais aproximada para o termo em português seja a de catador de lixo e recicláveis.

Em Debat: Rev. Dig., ISSNe 1980-3532, Florianópolis, n. 8, p. 38-53, jul-dez, 2012.
} 
registrar e apresentar aqui todas as assistências sociais desenvolvidas pelo Estado argentino, algo sem precedentes históricos no capitalismo, ao longo desse intenso período de lumpemproletarização, no entanto algumas podem ilustram esse quadro: ${ }^{9}$

Desde 1991 e durante a década seguinte se implementaram ao redor de 20 programas de emprego transitório, dirigidos principalmente a contratação de desempregados, que recebiam uma "ajuda econômica não remunerativa" por parte do Estado, para obras de interesse comunitário. Nessa linha de ação, em 1992, o governo nacional lançou o Plano Federal de Solidariedade dirigido a mais de três milhões de pessoas de "setores carentes" dos bairros com maior densidade populacional e sem recursos econômicos de todo o país. Projetou a criação de polos produtivos (2.400.000 pessoas), pôs em marcha o cultivo de verduras e hortaliças em hortas comunitárias, criação de granjas modelo, o desenho de minifúndios para famílias ou indivíduos proprietários de terrenos de reduzidas dimensões nas províncias menos desenvolvidas (que em conjunto com as hortas deviam abarcar a 400.000 personas) e o estabelecimento de micro empreendimentos produtivos para apoio da instalação de pequenas empresas de bens e serviços (entre 5 y 15.000 pessoas); em desenvolvimento integral para a GBA e a Grande Rosário se abarcaria entre 60 e 80.000 pessoas. Contudo, o grande incremento do desemprego, que teve um pico em 1995, obrigou a buscar também outras alternativas: o governo nacional anunciou um conjunto de programas de emprego que em 18 meses alcançariam a 870.000 desempregados. Também anunciou que uns 25.000 desempregados trabalhariam em dependências do exército onde realizariam tarefas de manutenção e outros 10.000 seriam ocupados tarefas de florestamento, dentro do "Programa de Empregos Mínimos", com uma retribuição de até 200 pesos (CARRERA, CAVALLERI \& MURRUNI, 2010, p. 137-138).

\section{Juventude e contestação social}

Antes mesmo de partimos para uma análise sobre a lumpemproletarização juvenil na GBA, discorreremos brevemente sobre o processo de deslocamento territorial das classes trabalhadoras lumpemproletarizadas como resultado da pauperização generalizada, causada pela acumulação integral, na GBA. ${ }^{10}$ A intensa marginalização na divisão social do trabalho de milhares de pessoas, aliada ao imenso sucateamento dos meios de transporte coletivo (no qual as ferrovias ${ }^{11}$ ganham destaque) que ligavam as

\footnotetext{
9 Para maiores informações sobre o uso político de políticas sociais na Argentina desse contexto Cf. DINATALE (2004).

10 "Durante o último governo militar se dispôs a erradicação das favelas da Cidade de Buenos Aires. A população deslocada se radicou no conurbano bonaerense. Assim mesmo, também durante dito governo se introduziram mudanças na política urbana que impediram a ocupação de parcelas que não contavam com infraestrutura e equipamento. $\mathrm{O}$ efeito de ambas políticas foi um deslocamento dos bairros pobres urbanos para a periferia e a densificação dos bairros pobres, e um incipiente processo de ocupação de terras" (SUÁREZ \& ARCE, 2010, p. 28).

${ }^{11}$ Para melhor visualizar o processo de sucateamento das ferrovias argentinas Cf. SOLANAS (2008).

Em Debat: Rev. Dig., ISSNe 1980-3532, Florianópolis, n. 8, p. 38-53, jul-dez, 2012.
} 
diversas regiões do conurbano bonaerense ${ }^{12}$ à capital federal serão responsáveis por um verdadeiro processo de periferização social visto que

ao final dos anos noventa, se consolidou no conurbano um novo padrão urbano que reflete uma forte polarização social. De um lado, as camadas médias e altas de maiores recursos habitam os novos subúrbios, se deslocam em carros particulares e ascendem a novos espaços de centralidade comercial e de ócio. Por outro lado, os grupos de menores recursos se assentam em habitações precárias, em urbanizações com profundas carências na dotação de infraestruturas e serviços, que tem nas linhas férreas como eixo de deslocamentos e tem seus círculos de satisfação de necessidades próximos a seus bairros (SUÁREZ \& ARCE, 2010, p. 32).

Algumas cifras nos permite afirmar que ao longo das últimas quatro décadas o conurbano bonaerense se converteu em uma região essencialmente lumpemproletária, visto que em 1974 5,8\% da população se encontravam abaixo da linha de pobreza; em 1980 se eleva para os 12,8\%; em 1982 atinge 37,4\%; em 1985 cai para 24\%; em 1987 volta a crescer e atinge os 33,1\%. Acredita-se que entre os anos de 1980 a 1988, a pobreza cresceu em torno de 50\% no conurbano bonaerense, atingindo em 1988 aproximadamente 3.218.000 pessoas. ${ }^{13}$ De acordo com os Estudos Permanentes de Lares, no ano de 1988 22,5\% dos lares se encontravam abaixo da linha da pobreza e no ano de 2002 (ápice da crise generalizada) esse número atinge a cifra de 42,3\%. Entre esses mesmos anos a porcentagem de pessoas vivendo abaixo da linha da pobreza sobe de $29,8 \%$ para $54,3 \%{ }^{14}$

O processo de periferização social a que foi submetido milhares de pessoas no conurbano bonaerense a partir da ditadura militar impulsionou uma grande quantidade de ocupação ilegal de terras nas regiões mais distantes da região metropolitana de Buenos Aires. A ocupação massiva de terras foi realizada com o apoio de diversas organizações sociais (ongs e comunidades eclesiásticas) e facilitou a emergência de um tipo de organização comunitária fundada no pertencimento territorial, no qual o bairro adquire importância fundamental. Desse modo, emerge nos bairros pobres dessas regiões uma grande quantidade de organizações populares que se mobilizarão para pressionar o poder público a promover as condições materiais necessárias para o acesso aos diversos serviços públicos essências a qualquer comunidade urbana (água encanada, energia elétrica, rede de esgotos, asfalto, escolas, creches, postos de saúde etc.). Em

\footnotetext{
12 "O conurbano bonaerense está composto por 24 municípios que envolvem a cidade de Buenos Aires. Concentra aproximadamente 9 milhões de pessoas, o que representa pouco menos de um quarto da população total do país. Junto com a cidade de Buenos Aires forma parte da região da Grande Buenos Aires - GBA" (SUÁREZ \& ARCE, 2010, p. 28).

${ }^{13}$ Jornal Clarín de 16/02/1997.

${ }^{14}$ INDEC, Estatística Permanente de Lares.

Em Debat: Rev. Dig., ISSNe 1980-3532, Florianópolis, n. 8, p. 38-53, jul-dez, 2012.
} 
resposta a essas condições materiais de existência irá emergir as primeiras organizações lumpemproletárias do conurbano, denominadas de Movimento de Trabalhadores Desempregados ou Movimento Piquetero, com o objetivo de exigir tais serviços sociais e trabalho digno.

Com a tremenda redução da produção industrial no conurbano, os espaços tradicionais de militância política se viram esvaziados. Os sindicatos sofreram um grande impacto, visto que seu elenco de manutenção fora praticamente dizimado, isto é, o trabalhador industrial que era a razão de ser e sustentáculo da burocracia sindical. Outra alteração política ocorrida nessas regiões diz respeito à relação que o peronismo passou a manter com o lumpemproletariado bonaerense. Tal relação foi marcada pelo clientelismo em torno da distribuição de políticas sociais. Na verdade, tais políticas clientelistas visava amenizar os descontentamentos sociais e os riscos de uma maior contestação social. Além disso, como tem ocorridos em diversos momentos históricos, a terrível miséria lumpemproletária foi aproveitada para os interesses políticos do peronismo. No entanto, com o intenso processo de lumpemproletarização a postura política do lumpemproletariado tendeu a se radicalizar e apontar para além das estruturas burocráticas dos partidos políticos e dos sindicatos. O que não significa dizer que tais estruturas não continuaram a existir e se aproveitar das lutas piqueteras, mas tão somente que as mesmas já não eram as únicas, ${ }^{15}$ pois uma quantidade expressiva de movimento de desempregados passou a se auto organizar comunitariamente e independente das estruturas burocráticas e hierárquicas de partidos e sindicatos (SVAMPA, 2010).

O movimento piquetero possui uma dupla origem: inicialmente ele emerge nas regiões petroleiras de Cutral-Co e Plaza Huincul (1996-97), em Neuquén, Mosconi e Tartagal e em Salta (a partir de 1997) que sofreram terrivelmente com o crescimento vertiginoso do desemprego a partir do processo de privatização da empresa petrolífera estatal YPF - Yacimientos Petroliferos Fiscales. Posteriormente, os métodos e ações organizativas do movimento piquetero que emerge nessas regiões se difundem por várias regiões do país, chegando até a capital federal e sua região metropolitana (GBA). Focaremos nossa análise apenas nessa última origem, isto é, nas ações dos movimentos piqueteros da GBA.

\footnotetext{
${ }^{15}$ Sobre as práticas clientelistas do Partido Justicialista (peronista) e o oportunismo do sindicalismo nesse contexto Cf. FERRERO (2007) e SVAMPA (2010).

Em Debat: Rev. Dig., ISSNe 1980-3532, Florianópolis, n. 8, p. 38-53, jul-dez, 2012.
} 
Marginalizado na divisão social do trabalho, o lumpemproletariado bonaerense necessitou encontrar formas de protesto que lhe retirasse do esquecimento social e pressionasse o poder público a realizar medidas que os retirassem daquela condição, ${ }^{16}$ portanto se viram obrigados a prejudicar a circulação de mercadorias e pessoas obstaculizando as principais ruas e estradas que ligavam a Capital Federal a outras regiões do país. Deste modo, a ação direta no bloqueio de ruas e estradas consistia nos principal método de agir do movimento piqueteiro. $\mathrm{O}$ ato de bloquear ruas e estradas de forma eficiente exigia outras formas organizativas no movimento piqueteiro, tais como deliberar sobre os bloqueios, formar comissões específicas para cada ação, tal como comissões responsáveis por garantir a segurança nos piquetes e promover $\mathrm{o}$ enfrentamento contra as forças repressivas etc. Todas essas deliberações ocorriam em assembleias nos bairros onde todos participavam e decidam de forma horizontal e auto organizados.

A juventude bonaerense constitui o grupo etário que, majoritariamente, já inicia seu processo de ressocialização (cf. VIANA, 2009a) marginalizada na divisão social do trabalho ${ }^{17}$ e com uma forte tendência a consolidar-se nessa condição, quer dizer, o processo no qual ela se prepara para realizar uma integração completa na sociedade já ocorre em condições de inteiro despojo da propriedade sobre suas condições materiais de existência. Consequentemente, se vê impossibilitada de reproduzir sua vida com seus próprios meios de produção, não conseguindo obter regularmente seus meios de vida sob a forma salário. Portanto, a intensa lumpemproletarização faz com que esse processo de ressocialização ocorra em condições de grande incerteza, instabilidade,

\footnotetext{
${ }^{16}$ Aqui o lumpemproletariado argentino revela seu interesse imediato, isto é, sair da condição de classe marginal, no entanto, esse não é o único interesse do lumpemproletariado, pois algumas organizações lumpemproletárias radicalizaram suas ações e apontaram para a necessidade de superar as relações de sociabilidade tipicamente capitalistas, revelando assim, sua potencialidade contestadora e a possibilidade de contribuição para uma luta de caráter anticapitalista. Sistematizaremos essa tese em trabalhos posteriores.

17 "Uns poucos dados permitem aproximarmos ao volume dessa população: segundo um informe oficial, na Argentina em 2000 os 13,2\% (1.250.841) das 9.476 .069 pessoas entre 15 a 29 anos não estudavam nem trabalhavam e do total desses jovens, 54,9\% (5.202.000) não assistia a nenhuma instância do sistema educativo. Quatro anos depois, superada a crise, os 17,4\% (204.195) dos jovens que habitavam a província de Buenos Aires e tinham entre 14 e 18 anos não frequentavam a escola ( $34 \%$ se se estende aos que tinham 21 anos); $2,3 \%$ (12.382) eram analfabetos; é possível que uma parte deles não frequentasse a escola, mas trabalhava. Essa situação é mais grave entre os pobres: em 1999, por exemplo, os $20 \%$ (400.000) dos jovens de lares pobres radicados na Capital federal e na Grande Buenos Aires não estudava nem trabalhava; entre os de 20 e 24 anos a porcentagem ascendia a $24,8 \%$, que não estudava nem trabalhava; nesses lares o desemprego juvenil chegava a 50\%. Em 2010 existem 1,5 milhões de jovens menores de 30 anos que não estuda nem trabalha" (CARRERA, CAVALLERI \& MURRUNI, 2010, p. 119).

Em Debat: Rev. Dig., ISSNe 1980-3532, Florianópolis, n. 8, p. 38-53, jul-dez, 2012.
} 
medo, frustração e revolta. Tais condições foram amplamente canalizadas para a luta no movimento piqueteiro.

A condição de classe marginalizada da divisão social do trabalho tende a gerar nos indivíduos que a ela pertence um sentimento negativo acerca das suas potencialidades, assim como uma autoculpabilização por sua condição de desempregado e uma autoestima baixíssima. Nesse sentido, o trabalho na realização dos bloqueios de ruas (piquetes), na sua manutenção por vários dias, na garantia da segurança dos que se mantêm ali, bem como o trabalho em empreendimentos autogestionados e participação ativa nas assembleias nos bairros contribuem para a construção de um sujeito coletivo e solidário. Segundo Vitullo,

na divisão de tarefas efetuadas entre os integrantes de cada agrupação, quando são criadas as diferentes comissões que se encarregam da segurança, das relações com a imprensa, da biblioteca, dos refeitórios, das oficinas, de organizar atividades para arrecadar fundos, os mais jovens sempre cumprem alguma função importante. Muitos optam por militar nas comissões de segurança, em que canalizam seu espírito de rebeldia e alimentam uma nova mística em seus enfrentamentos com as forças repressivas do Estado. Nos cortes eles podem demonstrar sua coragem e exteriorizar o profundo ódio que sentem pela polícia, única e perversa dimensão para eles visível da estatalidade, a que conhecem a partir das perseguições de que são objeto, levadas a cabo quase diariamente pelos agentes policiais do "mete bala" (gatillo fácil), dos fuzilamentos, da tortura e da permanente discriminação por "portación de cara". Mas os adolescentes e vinteaneiros não servem apenas de frente de choque para parar a repressão. Vários deles tem alcançado lugares importantes na direção do movimento, protagonizando as instâncias de debate político e tomada de decisões. São muitas as agrupações encabeçadas por militantes com menos de 30 anos, principalmente as independentes, aquelas que rejeitam qualquer relação orgânica com partidos e sindicatos (2008, p. 132).

A citação acima e, de igual maneira, diversos documentários produzidos por determinados movimentos piqueteiros demonstram claramente a forte presença de jovens nos protestos sociais. O documentário produzido pelo Grupo Alavio e denominado Crónicas de libertad - organizando la resistência (2002) apresenta um dos maiores e mais violentos enfrentamento entre as forças repressivas e diversos movimentos piqueteiros durante a tentativa de bloqueio da Ponte Pueyrredon, no dia 26 de junho de 2002. Ao assistir tal documentário é possível visualizar em suas imagens a participação maciça da juventude em confronto com a polícia, assim como seus depoimentos sobre as razões do episódio:

Piqueteiro capucha azul (entre 18 a 21 anos) - "Estou a sete meses no movimento, não terminei meus estudos e não tenho nada. Somos um grupo de pessoas que estamos desempregados, que necessita de trabalho e ter o que dar para seus filhos; que quer ter trabalho e o governo não nos dá, que estamos discriminados [...] estou nesse movimento porque não tenho 
trabalho, nem estudo, nem nada [...] no dia do ocorrido na Ponte Pueyrredon fomos exigir mais subsídios de alimentos para cada um de nós, para cada companheiro, pois um subsídio de 150 pesos não é nada [...] o governo não ia permitir que bloqueássemos a ponte, já se sabia na entrada que haveria repressão, mas agente não se importou, pois temos fome e seguimos cada vez mais. Quando descemos vimos que existiam helicópteros ali, que estavam com câmeras nos filmando. Sabiam para onde íamos e para onde não íamos [...] me encontrava assustado porque pensava na minha família, que algo poderia me acontecer, mas não me importava pois vejo a fome que minha família passa em casa, não temos trabalho (pausa para um suspiro emocionado) e portanto resolvi ficar ali, se eu perder, perdi".

Piqueteira hermosa (entre 24 a 27 anos) - "Se me encontro nesse movimento é porque as portas de vários lugares estão fechadas para mim por não ter estudo, por não ter muitas vezes o que vestir corretamente. Não me sinto envergonhada por estar nesse movimento, me sinto orgulhosa porque aprendi a valorizar muitas coisas que antes não valorizava [...] temos que pensar nisso, o que ocorreu no dia 26 é como voltar a vive-lo, me passa a cada momento da minha vida quando recordo tudo que aconteceu. Quando me sinto em casa com toda minha família ou quando vou dormir e sonho com isso é como se não tivesse ocorrido a muito tempo, é como ocorresse ontem, hoje ou ocorrerá amanhã. No dia 26 de junho quando saí da minha casa, saí chateada e não sabia porque [...] era como se eu pressentisse que algo feio ia ocorrer, quando fomos caminhando em direção à ponte encontramos muitos policiais, retrocedi e comecei a chorar e queria voltar para casa e ficar com minha mãe [...] Jamais em minha vida tive tanto medo como nesse dia, não tinha força para correr e a fumaça me asfixiava e tive muito medo pelo que levo aqui dentro (aponta para a barriga mencionando que se estava grávida) e pensava (chorando nesse momento) no que poderia acontecer".

Piqueteiro capucha negra (Entre 28 e 33 anos) - "O MTD - Movimento de trabalhadores desempregados, para nós é um movimento que se foi formando com a gente, pela necessidade que temos, digamos pelas pessoas que não tem uma renda e mediante as lutas tratamos de conseguir o pouco que estamos conseguindo. Eu estou no movimento há dois anos, dois anos e pouco [...] sabíamos que iria atuar no bloqueio da ponte a coordenadoria dos movimentos piqueteiros, o bloco piqueteiro, a CTA. um monte de grupos piqueteiros, digamos, mas havia alguma noção que supostamente ocorreria uma repressão [...] nesse movimento nós temos reuniões, analisamos as condições de onde vamos bloquear, com quem podemos nos encontrar, vemos uma forma de saída, pois em algum lugar podemos topar a repressão, um desalojo [...] havia muitos operativos policiais que paravam os coletivos (no qual muitos piqueteiros se transportavam até a região do bloqueio), camionetes suspeitas, até que chegamos à estação avellaneda, ali se foi formando alguns grupos, grupos de todas as organizações [...] na descida de Pavón (rua), a polícia, a infantaria, e um pouco mais adiante da ponte velha no fim da Mitre (rua) estava a prefectura (espécie de polícia militar naval) [...] do lado de Mitre vinha outra coluna de piqueteiros e entre as duas colunas ficou a coluna da polícia, mas que aconteceu? Em algum momento a coluna da polícia saiu da rua e foi para a calçada e quando as duas colunas piqueteiras iriam se encontrar a polícia entrou novamente no meio da rua e quando aproximamos eles começaram a se defender com os escudos e nos provocaram dando cacetadas, daí tentamos evitar que a polícia caminhasse em direção a Pavón e a gente começou a sair para o lado de Pavón, à medida que nos encontramos entre Pavón e Mitre ali estava disposto o grupo da prefectura daí juntaram as duas colunas policiais e começaram a avançar em nossa direção".

Piqueteiro capucha rubro-negra (aproximadamente 30 anos)- "É fodido analisar o que aconteceu no dia 26, não? Sobretudo porque foi minha primeira repressão desde que tomei consciência e comecei a lutar pelo que creio é digno por trabalho e mudança social. Começamos do zero porque não temos nada, somos marginais [...] Somos piqueteiros, na verdade somos

Em Debat: Rev. Dig., ISSNe 1980-3532, Florianópolis, n. 8, p. 38-53, jul-dez, 2012. 
responsáveis pela segurança dos piquetes, porque piqueteiros somos todos nós (aponta para os companheiros em volta). Dentro de um piquete a totalidade dos companheiros tem funções e a nossa é blindar e dar segurança da melhor forma e para pertencer a essa área simplesmente o companheiro tem que ter vontade e um pouquinho de consciência do que estamos fazendo, pelo que estamos lutando e a função que temos como seguranças [...] temos tido piquetes onde diretamente vem patrulheiros e atropelam o que vem pela frente e por isso fazemos barricadas e colocamos tudo que podemos colocar para bloquear e evitar que isso aconteça [...] e reforçamos o capuz depois que acontece as coisas porque vimos que o capuz é símbolo da rebeldia que representamos no sentido de que este governo filho da puta para nos deixar sem trabalho não nos olha na cara e quando não tenho pra dar o que comer para meus filhos tão pouco chega um funcionário público e me olha na cara e diz toma aqui o que comer, o governo não nos dá nada apenas nos tira sempre, então, sim somos rebeldes e tampamos nossa cara”.

Para concluir, o pouco que foi apresentado sobre o processo de lumpemproletarização juvenil e contestação social na GBA é suficiente para reforçarmos duas teses centrais acerca do lumpemproletariado e seu grupo etário juvenil, ou seja, ao contrário do que afirma determinadas ideologias contemporâneas (principalmente o leninismo), tal classe social possui na atualidade uma tendência a ampliar seu poder de contestação social e compor uma aliança com o proletariado que pode e deve contribuir para uma revolução social que garanta o processo de construção de uma sociedade verdadeiramente humana fundada na autogestão social e nesse processo a juventude possui um papel fundamental visto que sua disposição e interesse em transformar a realidade alimenta a contestação social.

\section{Referências bibliográficas:}

Grupo, Alavio. Crónicas de libertad - organizando la resistência. Buenos Aires, 2002. $1 \mathrm{dvd}$ de vídeo (47 min.).

BASUALDO, Eduardo. Concentración y centralización del capital en la Argentina durante la década del noventa. Quilmes: Universidad Nacional de Quilmes Ediciones, 2002.

BRAGA, Lisandro. Gatillo fácil - uma politica de contrarrebelião preventiva na Argentina (1996-2011). Revista Crítica do Direito, número 2, volume 44, 01 de janeiro a 04 de fevereiro de 2013.

Classe em farrapos - acumulação integral e expansão do lumpemproletariado. São Carlos: Pedro e João editores, 2013a. 
CARRERA, Nicolás, CAVALLERI, Stella \& MURRUNI, Marina. La superpoblación relativa en Argentina actual: um ejercício de medición. Buenos Aires, Publicación de Programa de Investigación sobre el Movimiento de la Sociedad Argentina - PIMSA, número 13, 2010.

DINATALE, Martín. El festival de la pobreza - el uso político de planes sociales en la Argentina. Buenos Aires: La Crujía, 2004.

FERRERO, Roi. La lucha de clases en Argentina - entre la revolución proletária y la recuperación burguesa. Florianópolis: Editora barba ruiva, 2007.

HARVEY, David. Condição pós-moderna. São Paulo: Edições Loyola, 2008. . Neoliberalismo - história e implicações. São Paulo: Edições Loyola, 2008a. O novo imperialismo. São Paulo: Edições Loyola, 2011.

Programa de Investigação sobre o Movimento da Sociedade Argentina. Em: http://www.pimsa.secyt.gov.ar/ Acessado em: 25/03/2013.

SIDICARO, Ricardo. Los tres peronismos - Estado e poder econômico. Buenos Aires: Siglo veintiuno editores, 2010.

SILVER, Beverly. Forças do trabalho - movimentos de trabalhadores e globalização desde 1870. São Paulo: Boitempo, 2005.

SOLANAS, Pino. La próxima estación - reconstruir el tren para todos. Buenos Aires, 2008. 1 dvd de vídeo (115 min.).

SUÁREZ, Ana Lourdes \& ARCE, Carolina. Condiciones de vida en el conurbano bonaerense. Em: ROFMAN, Adriana. Sociedad y territorio en el conurbano bonaerense. Los Polvorines: Universidad Nacional de General Sarmiento, 2010.

SVAMPA, Maristella. La sociedad excluyente - La Argentina bajo el signo del neoliberalismo. Buenos Aires: Taurus, 2010.

VIANA, Nildo. O capitalismo na era da acumulação integral. Aparecida, SP: Ideias e Letras, 2009.

Em Debat: Rev. Dig., ISSNe 1980-3532, Florianópolis, n. 8, p. 38-53, jul-dez, 2012. 
VIANA, Nildo. Juventude e identidade. Revista Estudos. Goiânia, volume 36, n. 1/2, jan./fev. de 2009a.

. A teoria das classes sociais em Karl Marx. Florianópolis: Bookess, 2012.

VITULLO, Gabriel. Teorias da democratização e democracia na Argentina contemporânea. Porto Alegre: Editora sulina, 2008. 